\title{
Repertorio Americano en la web: del texto impreso al texto digital
}

Carolina Gómez Fernández. Facultad de Filosofía y Letras Universidad Nacional

Margarita Rojas González Proyecto Biblioteca Electrónica Scriptorium

Facultad de Filosofía y Letras Universidad Nacional

\section{Resumen}

Se describe el proceso de digitalización de la revista Repertorio Americano, de Joaquín García Monge, llevado a cabo por el proyecto Biblioteca Electrónica Scriptorium de la Facultad de Filosofía y Letras. Se explica la diferencia entre el texto impreso y el texto digital. Se hace una breve síntesis de los diversos intentos de digitalización de la revista en el país.

Palabras claves: digitalización, revistas, Repertorio Americano

\begin{abstract}
We describe the digitizing process of Repertorio Americano journal, edited by Joaquín García Monge, done by Scriptorium Electronic Library Project, at Faculty of Philosophy and Arts. We explain the difference between printed text and digital text. We also synthesize the different purposes in order to digitize this journal in Costa Rica.
\end{abstract}

Keywords: digitizing, journals, Repertorio Americano 


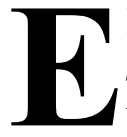

1 proyecto Biblioteca Electrónica Scriptorium pertenece a la Facultad de Filosofía y Letras; la segunda etapa dio inicio en 2011, a cargo de un equipo multidisciplinario. Como en muchas otras actividades universitarias, en el trabajo de este proyecto se recurre a la ayuda de estudiantes, tanto de horas asistente como de "horas colaboración" para tareas como el escaneo, la digitalización, la compilación de bibliografías y la búsqueda de imágenes. Sin embargo, cuando en 2012 hubo que enfrentar la enorme labor de digitalizar una revista de la magnitud de Repertorio Americano, se tomó la decisión de recurrir a una empresa profesional. Para resolver esta situación, además, se tuvo que buscar fondos específicos, aportados en esa ocasión por la Vicerrectoría de Investigación.

¿Por qué se hizo eso? Mientras que en la universidad generalmente se recurre a escáneres de menor tamaño y los estudiantes que los utilizan solamente han recibido una rápida capacitación, las empresas profesionales cuentan con programas especiales, técnicos con la preparación especializada, máquinas que no existen en la Universidad y también con experiencia acumulada. En este caso, por ejemplo, se trata de personal que había digitalizado la colección de periódicos del siglo 19 en la Biblioteca Nacional, que estaba en condiciones de preservación bastante frágiles.

Algo semejante ocurría con la revista de Joaquín García Monge; Repertorio Americano había sido donado a la UNA por el Banco Central, que deshizo la valiosa biblioteca en que había conservado su colección de revistas. La donación consistió en una colección completa empastada y varias colecciones de ejemplares sueltos. La rectoría decidió entregarlos en custodia en el Instituto de Estudios Latinoamericanos, el cual, sin embargo, nunca contó con las condiciones físicas para la debida conservación, incluso ahora (véase en anexos copia del acuerdo de rectoría sobre la donación). Esto también fue parte de la decisión de no escanearlos a mano con los escáneres pequeños.

La empresa contratada escaneó la colección completa de revistas correspondientes del período 1919-1959 y alcanzó también a escanear las del periodo 1974-1982, el primer período del Repertorio editado por el IDELA. A partir de entonces, a finales del año 2014, se inició el largo y complejo proceso para ingresar los números de $R e$ pertorio Americano en la web. Esta parte del trabajo, que casi siempre pasa en la invisibilidad, es la más cara por la cantidad de trabajo profesional invertido. Por eso es necesarios recordar que crear la versión digital de una revista impresa no consiste únicamente en escanearla; cuando no se hacen índices, metadatos ni descripciones, para un investigador consultar una revista o un periódico es casi lo mismo que verlo en un microfilm pues, o sabe exactamente cuál número necesita, o bien tiene que pasar página tras página para ir encontrando los datos buscados. Cuando se cuenta con índices y metadatos que describen cada artículo, ilustración y anuncio, en cambio, el investigador puede generar una lista de lo que requiere en segundos.

Por tanto, es útil subrayar el hecho de que subir imágenes de una revista es parte del trabajo pero no es todo el trabajo, sobre 
todo en un documento de las dimensiones de Repertorio Americano. Esta revista suma un total de 1.181 números que contienen 18.595 páginas; poder abarcar la totalidad en la edición impresa es prácticamente imposible, por esto los estudios realizados hasta ahora generalmente han sido sobre un tema o un autor. Solamente si se cuenta con los índices de cada tomo es posible encontrar información de todo lo publicado.

Ahora bien, la idea de poner esta revista a disposición del público con acceso gratuito no es nueva, ni en la UNA ni en el país. Desde hace aproximadamente treinta años en el Centro de Investigaciones en Identidad y Cultura Latinoamericana de la Universidad de Costa Rica (Ciicla) se empezó a analizar la posibilidad pero con la idea de hacerlo "en casa". Para esto se dieron a la búsqueda de recursos para adquirir un escáner aéreo. Muchos años después consiguieron los fondos, unas bibliotecólogas se capacitaron y subieron 66 tomos, al principio con una resolución regular, luego en blanco y negro. Esta versión, como se puede constatar en el sitio del Ciicla, no contiene índices ni metadatos ${ }^{1}$.

En la Universidad Nacional, años atrás, la iniciativa partió del área bibliotecológica y se dirigió más bien hacia la indización de Repertorio. Por un lado, Lucía Chacón organizó primero un proyecto en el que lograron indizar más de 4.000 registros; por otro lado, una bibliotecóloga de la Facultad de Filosofía y Letras junto con otra colega llevaron a cabo en 1996 un trabajo de graduación en el que describieron todas las

1 En la sección BIBLIOTECA DIGITAL de http:// www.ciicla.ucr.ac.cr publicaciones hechas por mujeres en la revista $^{2}$. Por último, Repertorio Americano fue uno de los primeros documentos microfilmados en el Sistema Nacional de Bibliotecas, donde también se inició la labor de su indización, sin haber llegado a concluirla.

De todos estos intentos, el que lo culminó fue el del proyecto Scriptorium. Ahora bien, cuando la empresa entregó los archivos escaneados surgió otro dilema: ¿cuál podría ser la mejor manera para subir a la web los documentos? La empresa había digitalizado las revistas en formato pdf, también convirtió algunas páginas como imágenes en formato jpg.

Entonces se solicitó el apoyo del área UNA-Web con la que después de múltiples análisis de las distintas opciones, se decidió subir cada número de la revista como un documento individual al repositorio institucional de la Universidad Nacional. Esto marca una diferencia con respecto a la forma en que normalmente se suben las revistas contemporáneas: en estas se distinguen los artículos independientes, lo cual era muy complicado en el caso de Repertorio debido a la disposición interna de los artículos: generalmente terminan en una página distinta a la que empiezan.

El repositorio institucional se hizo con el programa DSpace, el cual es un software de código abierto que permite la administración de colecciones digitales. Por su

2 Mirna Murillo Ch. y Yenory Rodríguez M., Índice analitico sobre artículos escritos por mujeres y editados en la publicación seriada Repertorio Americano desde 1919 hasta 1959, memoria de la práctica de graduación de Licenciatura en Bibliotecología, 3 tomos, San José: Universidad de Costa Rica, 1996. Se puede consultar en línea en el minisitio Mujeres en Repertorio Americano, www.scriptorium.una.ac.cr. 
lado, el sistema de bibliotecas de la Universidad Nacional (SidUna) trabaja con el sistema OPAC (en inglés Online Public Access Catalog), que es un catálogo automatizado de acceso público en línea de los materiales de una biblioteca. Con el fin de permitir la interacción de ambos sistemas se adquirió la herramienta OAI la cual permitiría que los datos de un programa se "cosechen" en el otro; sin embargo, todavía no se ha logrado la comunicación entre los sistemas y, por motivos ajenos al equipo de Scriptorium, tampoco se han podido visualizar los datos del Aleph (OPAC de la UNA) en la web.

Ahora bien, a pesar de los esfuerzos realizados y el profesionalismo empleado por todos los participantes, en el proceso siempre se requiere control de calidad. Sobre la división de Repertorio Americano: como se sabe, el primer número de Repertorio Americano se publicó el primero de setiembre de 1919. El tomo I, que va del 1 de setiembre de 1919 al 1 de de agosto de 1920, contiene 24 números y 372 páginas. A lo largo de los 40 años que duró la revista, los tomos contienen un número variable de números. También la periodicidad fue variable.

Cuando se realizó el control de calidad, al finalizarse el proceso de la elaboración de los índices, se comprobó que había varias revistas que no se habían escaneado completamente y también se verificó que faltaban varias páginas en algunos números. Entonces se decidió llevar a cabo varios procesos para remediar esas carencias:

- para completar las páginas faltantes estas, se escanearon; se dividieron los documentos en pdf con el fin de agregar las nuevas imágenes, se volvieron a crear los pdf y se minimizó el tamaño para poder agregarlo al repositorio. Además, se incluyeron las páginas faltantes en el índice.,

- para completar los números, se escanearon las revistas que faltaban, se digitalizaron las imágenes para que todas tuvieran el mismo tamaño, se crearon los pdf y se minimizó el tamaño para poder agregarlo al repositorio, además, se realizaron los índices respectivos.

Otro detalle importante es lo que se refiere a la numeración seguida por la revista: $R e$ pertorio Americano se identifica mediante una fecha, un número y un tomo. En este orden, se descubrió que existían números y tomos repetidos lo cual generó cierta confusión a la hora de realizar los índices.

En vista de que la prioridad era ofrecer un servicio de calidad para los usuarios cuando consulten en los motores de búsqueda de la web información sobre Repertorio Americano, el equipo de Scriptorium decidió realizar un índice de cada revista, para poder consultar la información desde el repositorio institucional. Los índices de las 1.170 revistas correspondientes a los años de 1919 a 1959 se subieron a la web en un periodo de aproximadamente doce meses, sin contar las vacaciones de diciembre 2014 y enero 2015; en ese proceso además de las jornadas de las profesionales del equipo colaboraron tres estudiantes asistentes y nueve estudiantes de horas colaboración.

Aunque el proceso de elaboración de índices fue extenso, se debe destacar la 
reacción positiva de los estudiantes al ver los resultados así como al conocer por diferentes medios de comunicación (periódicos La Nación y Campus, reportaje en el canal de la Universidad de Costa Rica) que el trabajo realizado es útil, no solo para la comunidad universitaria sino también para la comunidad mundial.

Al realizarse los procesos anteriormente indicados, se dio por terminada esta etapa de la publicación de Repertorio Americano en la web. Actualmente se puede buscar información de la revista en motores de búsqueda como Google, Bing, Yahoo y Yandex, el motor de búsqueda utilizado en Rusia.

En relación con la segunda época de $R e$ pertorio Americano (1974-1982), durante los primeros meses de 2016 se crearon los índices. Así se logró poner más de mil documentos en la web con sus respectivos índices, lo cual significa un gran resultado; este, sin embargo, no implica que la mayoría de los potenciales usuarios sepan que la revista está allí, al alcance de la mano. Desde 1949, Repertorio Americano ha sido objeto de estudio de un restringido grupo de investigadores; por ejemplo, a lo largo de las cuatro décadas de existencia de la Universidad Nacional, durante las cuales se han llevado a cabo varias investigaciones sobre Repertorio Americano, desde los trabajos de filólogos e historiadores, como desde la óptica de estudios feministas ${ }^{3}$.

Uno de estos es la tesis de maestría de la profesora May Brenes, que estudia las publicaciones de mujeres escritoras

3 Ver la bibliografía específica en el minisitio MUJERES EN EL REPERTORIO AMERICANO, http:// www.scriptorium.una.ac.cr/index.php/mini-sitios/ mujeres-ra y políticas en Repertorio Americano. Se consideró que era necesario dar a conocer también este tipo de trabajos académicos llevados a cabo en la Facultad de Filosofía y Letras, lo cual es el principal objetivo de Scriptorium. Entonces se decidió construir también un "minisitio" y divulgar la presencia de la revista en la web. Asimismo, se utilizó el trabajo de Mirna Murillo y Yenory Rodríguez Índice analitico sobre artículos escritos por mujeres y editados en la publicación seriada Repertorio Americano desde 1919 hasta 1959. En este minisitio se incorporó por primera vez dentro de la tecnología de Joomla en la sección Cronología, herramientas como Tooltips, las cuales son ventanas emergentes que permiten tener información extra para ilustrar una temática.

En el repositorio institucional, gracias a la creación previa de los índices, se pueden realizar búsquedas temáticas, por ejemplo: para buscar la información se debe ir a la subcomunidad de Repertorio Americano y en la sección "Buscar en el Repertorio" se debe escribir una temática específica y seleccionar la opción en esta colección; de esta manera se podrán obtener los resultados buscados.

Durante casi un siglo, Repertorio Americano se podía leer y consultar en la versión impresa; cuando se empezó a digitalizar e indizar en los últimos tres años cada uno de sus números adquirieron otro género y cambiaron de dimensión: los mil ciento ochenta y un números independientes se convirtieron en un único documento.

Esto tiene profundas consecuencias en el orden de la investigación. Por un lado, 
significa que la revista puede abarcarse y analizarse en un tiempo mucho menor $y$, sobre todo, que por primera vez se puede comprender unitariamente. Con anterioridad, la capacidad humana limitaba la posibilidad de abarcar simultáneamente todos los ejemplares y se hacían, por lo tanto, estudios parciales, temáticos, se rastreaba por ejemplo la obra de un autor determinado, con el riesgo de dejar por fuera algunos ejemplares. El mismo y respetado creador y editor se equivocó algunas veces cuando numeraba las páginas o los números.

Las tecnologías actuales permiten no solo "ver" cada página de Repertorio Americano en una pantalla; esas van más allá de una máquina de microfilm ya que permiten generar índices a lo largo de todos los números en minutos y sin posibilidad de error. Por esto es importante comprender, en primer lugar, que la incorporación de la revista en la red mundial no implica solamente escanear las páginas; se trata de una operación mucho más compleja que comprometió el trabajo de varias especialidades y muchas horas de trabajo especializado para resolver nuevos y variados problemas que no se conocían anteriormente.

En segundo lugar, la digitalización permitió entender verdaderamente que Repertorio Americano no es solamente una revista de contenidos latinoamericanistas; fue un enorme proyecto editorial que talvez solamente ahora, con el auxilio tecnológico, logremos concebirlo como un único objeto de estudio, una red intelectual y artística, una secuencia a lo largo de cuadro décadas.

Por último, aunque talvez lo más importante, finalmente esta gran revista está al alcance de todos y no solamente para el estudio de pocos investigadores; es probable que esta forma garantice tanto una mejor preservación como un mayor alcance para la mayoría de la gente. Como lo quería su creador. 


\section{Copia del acta de donación de Repertorio Americano,} del Banco Central a la Universidad Nacional

Fecha: junio 1998, Archivo Consejo Universitario UNA

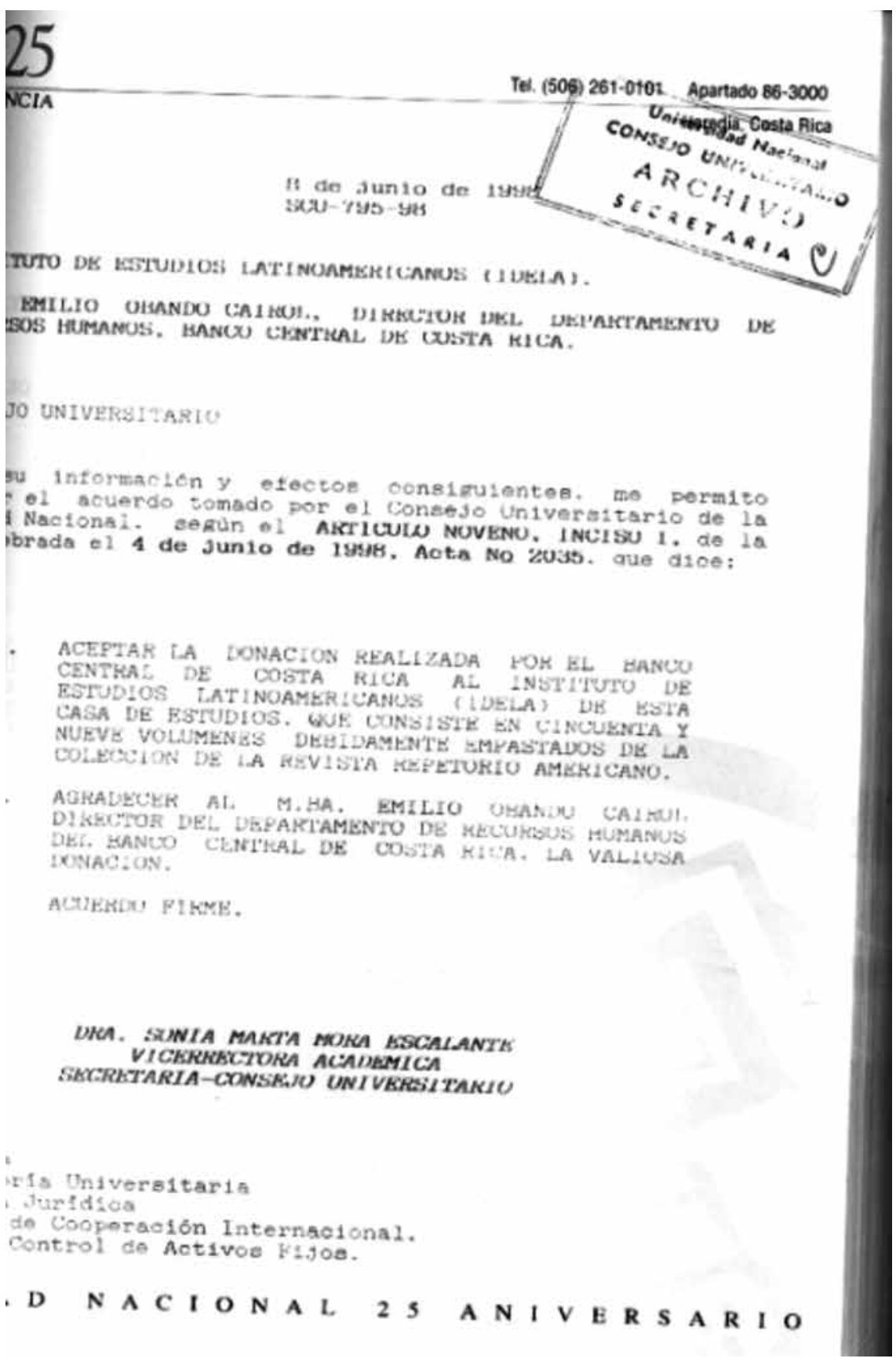




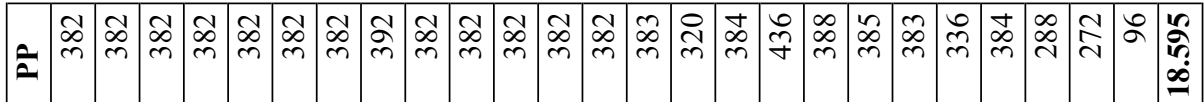

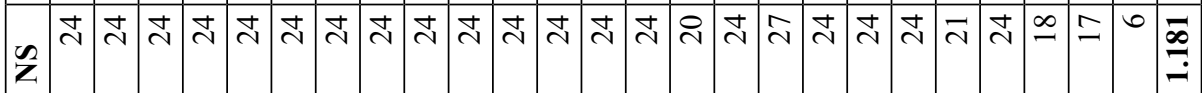

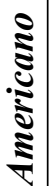

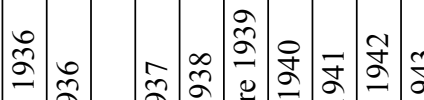

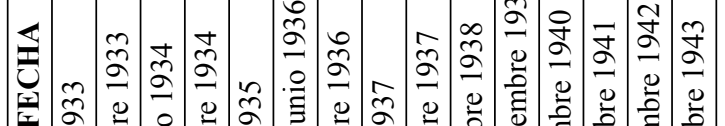

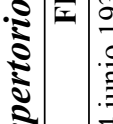

至

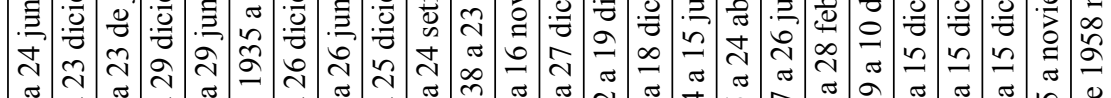

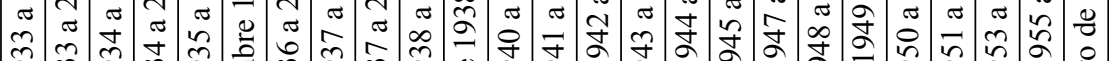

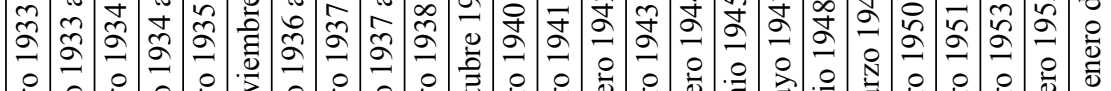

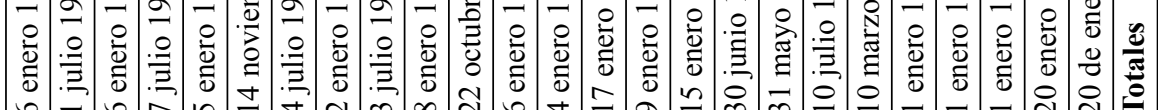

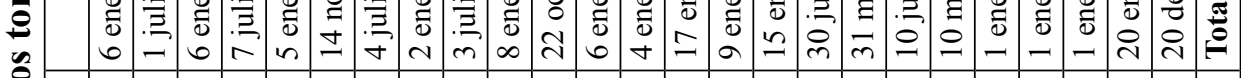

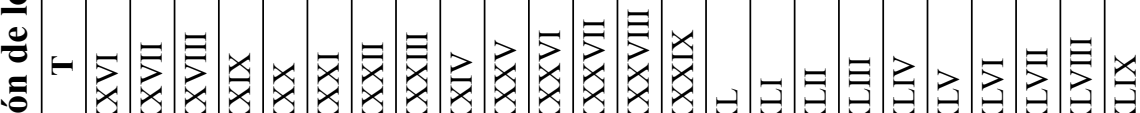

:

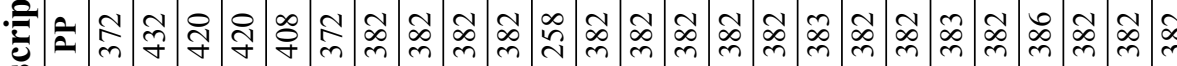

\&

它

Z

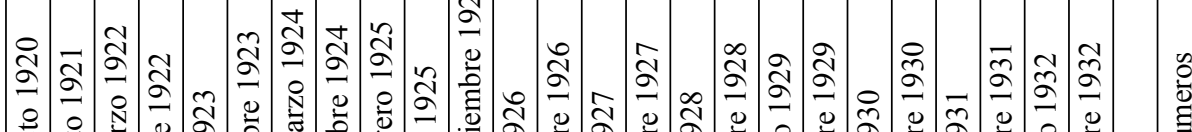

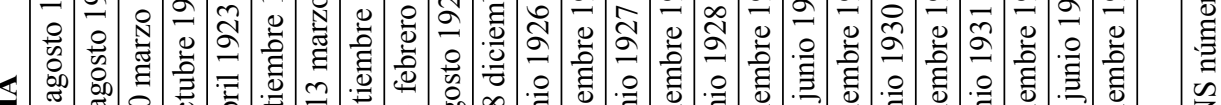

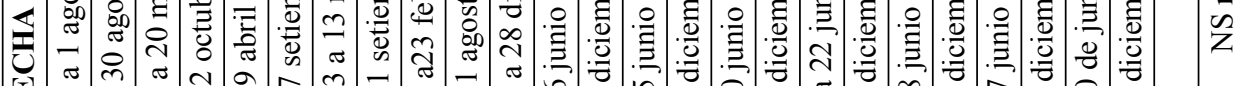

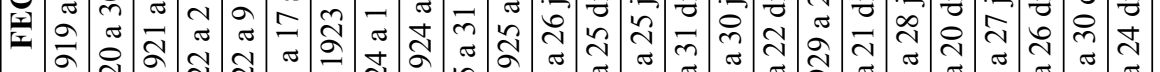

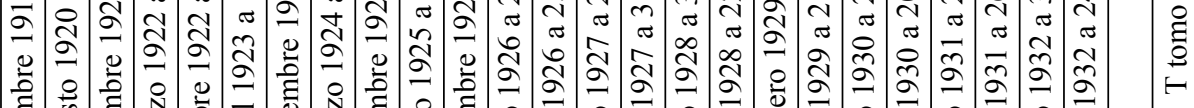

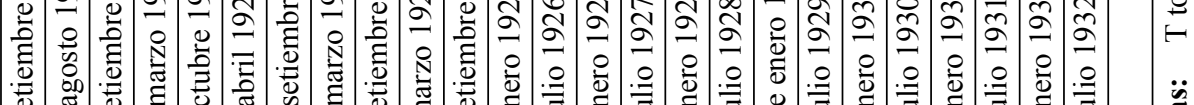

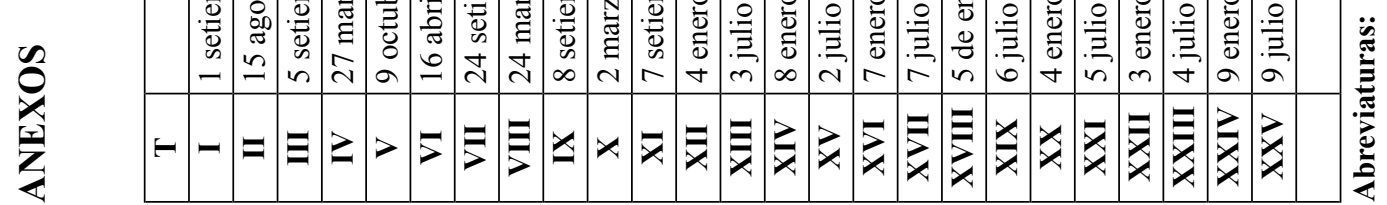




\section{Proceso de escaneo y digitalización de Repertorio Americano}

Lugar: Idela, Universidad Nacional

Fecha: 10 de noviembre de 2013

Aracelly Ugalde V. y Margarita Rojas G. del equipo Proyecto Biblioteca electrónica, Marco Aragón, Arrendadora Comercial
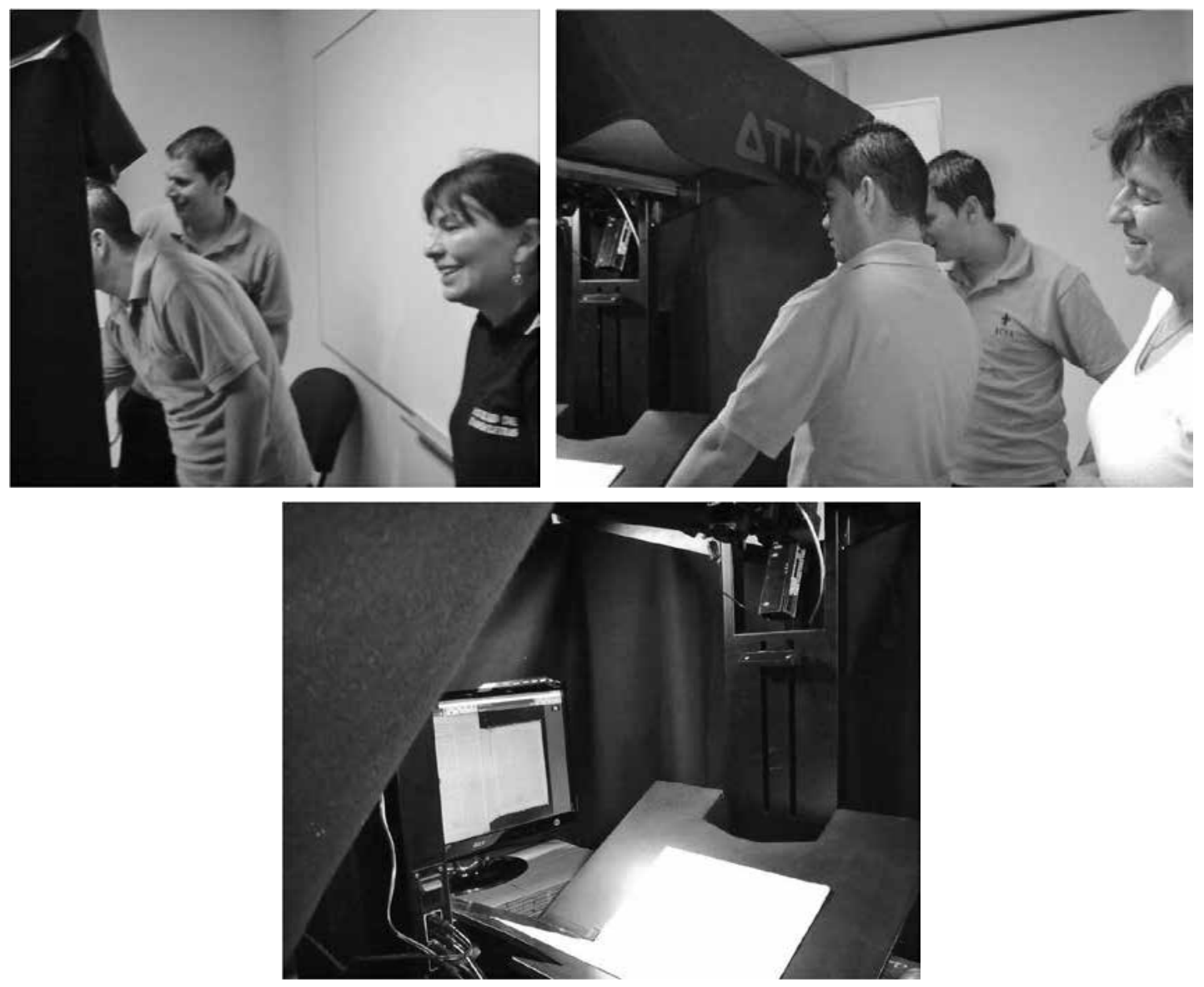


\section{Páginas de Repertorio Americano}

Fecha: 7 de abril de 1934, páginas 198 y 199, Proyecto Biblioteca electrónica Scriptorium
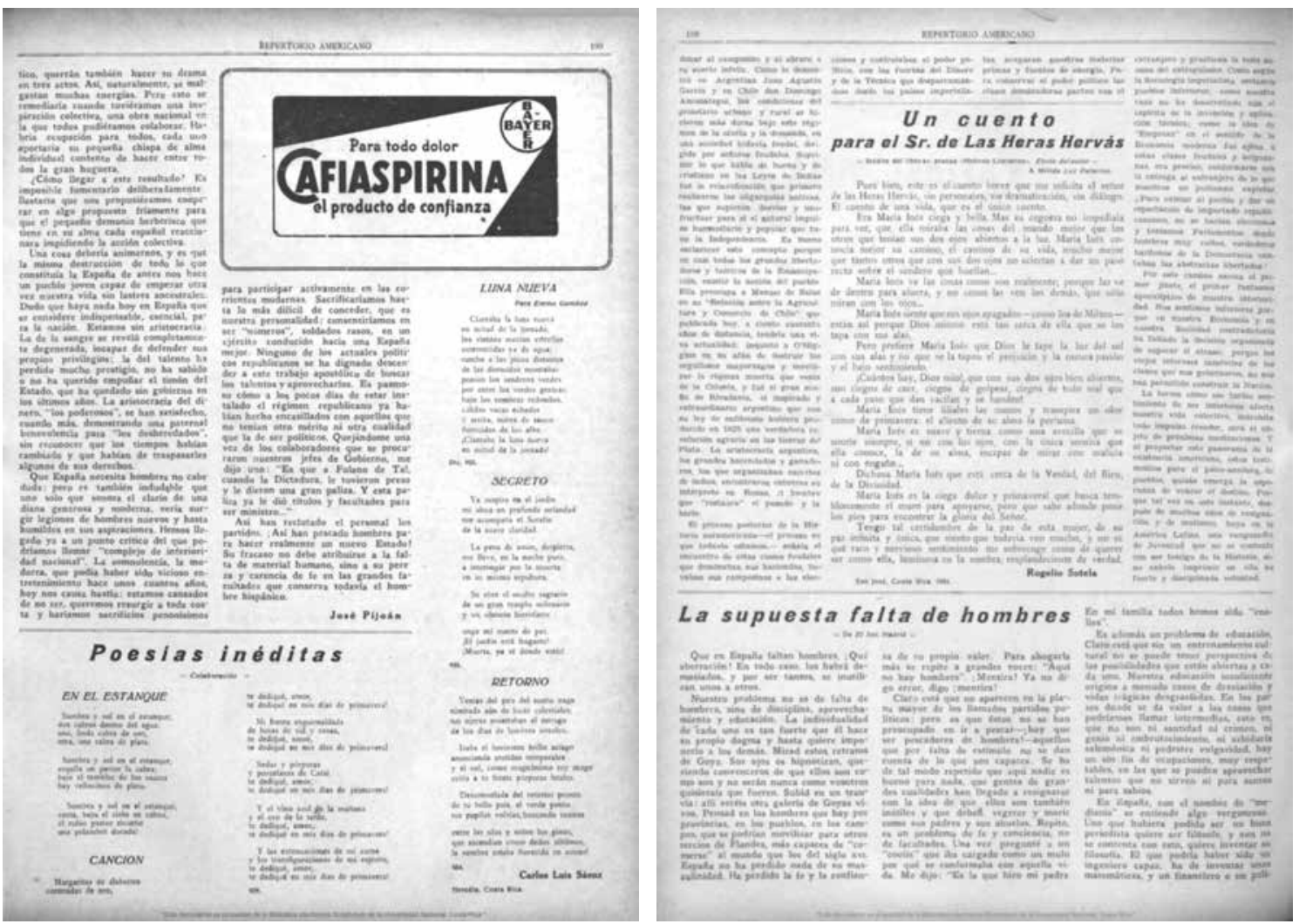